produced is proportional to the quantity of gas required. This is only partly true, as actually the temperature of the fire does not vary as quickly as the load on the engine may vary, and although there may be a considerable fall in the load, there is usually heat enough in the fire to produce more steam than is then desirable. If this excess of steam continues, it not only causes an excess of carbon dioxide to be formed, but it damps down the fire. Then, when the load is increased suddenly, the temperature of the fire is not high enough to develop the power required. Some makers of suction plants try to get over this difficulty by having regulating valves worked by the engine, by means of which the admission of steam to the fire is governed by the engine. Some merely allow a vent in the vapouriser for the excess of steam to escape when the load is reduced, some make no special provision at all, while others use the suction of the engine to draw water into the vapouriser in very small quantities, just enough at each suction-stroke to give the steam required for the quantity of gas to be consumed. This can only be done provided the vapouriser flashes the water into steam; if the vapouriser holds a body of water, as in a boiler, steam is given off continuously, and although there might be a governing of the feed-water, the quantity of steam produced would not be governed. J. EMERSoN Dowson.

$$
\text { (To be continued.) }
$$

\section{THE SCOPE OF EUGENICS.}

THE first edition of the Robert Boyle lecture "On the Scope and Importance to the State of the Science of National Eugenics," delivered by Prof. Karl Pearson in 1907 before the Oxford University Junior Science Club, being out of print, the author has re-issued the same through Messrs. Dulau and Co. as the first of a "Eugenics Laboratory Lecture Series," intended to place the purport of the investigations conducted in that laboratory before the public in a simple form. The series should serve a useful purpose, as many of the original memoirs are somewhat repellent even to a reader of rather more than average intelligence owing to the use of highly specialised statistical methods. A translation of the lecture into German, by Dr. H. Fehlinger, has been published by, the firm of Teubner (Leipzig and Berlin) in the Archiv für Rassenund Gesellschafts-Bíologie.

In the present lecture Prof. Pearson gives. in brief the whole eugenics argument. "The Darwinian hypothesis asserts that the sounder individual has more chance of surviving in the contest with physical and organic environment. It is therefore better able to produce and rear offspring, which in their turn inherit its advantageous characters. Profitable variations are thus. seized on by natural selection, and perpetuated by heredity." If these ideas apply to the case of man, "we must have evidence (I) that man varies; (2) that these variations, favourable or unfavourable, are inherited; (3) that they are selected.' On the first head special evidence is hardly necessary; our own eyes afford evidence day by day that man varies, but there is plenty of definite knowledge also as to the amount and magnitude of variation. There is similarly a growing mass of evidence that such variations are not mere individual fluctuations, but are heritable. On the third head, however, the evidence is weaker and somewhat conflicting. In the population at large, natural selection appears to be operative to a greater or less extent, as we find that the age at death is inherited. It would be quite possible, however, for that selection to be ineffective if the weaker stocks nevertheless survived to a sufficient age to reproduce their kind as freely as the stronger stocks, and this seems to be the case to a large extent. The families of deaf-mutes, the tuberculous, and the mentally defective are as large as those of normal individuals, and the lower we go from one social grade to another the higher does the fertility rise. In these facts lies the stimulus to possible action directed towards the betterment of the race, negatively by placing hindrances in the way of the reproduction of the hopelessly unfit, positively by creating an altered tone and public spirit which may lead to a more normal and less restricted reproduction of the prosperous and the intellectual classes.
If one sentence may be cited with special approval, it is a statement near the commencement of the lecture :"Our science does not propose to confine its attention to problems of inheritance only, but to deal also with problems of environment and of nurture." The improvement of the environment is as much a method of improving the qualities of future generations as the method of selection, not, of course, because somatic variations are heritable (which we do not believe that they are), but because the improvement of the environment endures. In so far as housing, education, and the treatment of the diseased are improved in this generation, the next starts from a fresh basis. Eugenic and eugeic methods should aid each other, and racial improvement be based on care of both the seed and the soil. Hitherto the methods have been too often treated as if they were opposed.

\section{SCIENTIFIC WORK OF THE LOCAL GOVERNMENT BOARD.}

THIS report ${ }^{1}$ of the Local Government Board is the first to be submitted by Dr. Newsholme, and in the introduction he pays a graceful tribute to the work of the retiring principal medical officer, Sir William Power.

The vaccination returns show a slight increase in the percentage of births vaccinated and of infants exempted percentage or bir "conscientious objection."

In the appendix on auxiliary scientific investigations carried out for the Board, Dr. Klein has continued his studies on immunity in plague, and shows that a watery extract of the liver and spleen of a rabbit which has recovered from an attack of plague possesses curative properties.

Drs. Andrewes and Gordon contribute a report on the defensive mechanisms of the body against infection by the pyogenic cocci, and, while admitting that the chief means of defence is a phagocytic one, conclude that the bacteriolytic power of the body fluids is by no means negligible.

Dr. Andrewes has also investigated the micro-organisms present in sewer air, with the result that the bacteria of sewage are to be found in the air of sewers and drains, and that therefore sewage in certain circumstances gives up its bacteria to sewer and drain air, though such bacteria ordinarily form but a small proportion of those present in sewer air. So far, the organisms detected are not in themsclves known to be prejudicial to health, but their themselves known to be prejudicia harmful sewage-borne mierobes may likewise gain access to sewer air.

Dr. Savage submits a report dealing with the bacterial contamination of milk as obtained from healthy cows, and with the examination of milk samples obtained from cows suffering from an inflammatory disease, garget (mastitis), of the udder. In another report he details the results of the ude an examination of the intestinal contents of domestic animals for bacteria belonging to the Gaertner group-organisms which cause certain outbreaks of meat poisoning. From three bullocks and six pigs the results were negative, but from a calf numerous organisms belonging to this group were isolated.

of late the view has been gaining ground that acute rheumatism is a microbial disease, and various organisms have been described by investigators. Dr. Horder contributes a report on the subject, but his results are mainly negative, and further research is evidently called for.

The action of the Streptococcus faecalis and of its chemical products has been investigated by Dr. Sidney Martin. The organism is capable of producing various disease conditions in man, such as cystitis and septicæmia. Preliminary experiments on the toxin of the microbe suggest that the main poisonous product is an endotoxin.

In an appendix Dr. Blaxall and $\mathrm{Mr}$. Fremlin record experiments on the effect of cold on the potency of vaccine lymph, and show that a temperature of $-180^{\circ} \mathrm{C}$. has no effect, and that lymph stored at $-5^{\circ} \mathrm{C}$. for a year suffered no diminution in potency.

It will thus be seen that the volume contains papers of considerable importance in scientific medicine and hvgiene.

\section{R. T. H.}

1 Thirtv-sixth Annua' Renort of the Lncal Government Roard, xوo6-7. Supplement containing the Report of the Medical Officer for 1906-7. 